\title{
The Influence of Attitude on Consumers' Autonomy to make Halal Food Purchase Intention: An Overview of Self-determination in a Collectivist Culture
}

\author{
Sumera Syed ${ }^{1}$, Fauziah Sh. Ahmad ${ }^{1}$, \& Syed Rashid Hussain Shah ${ }^{2}$ \\ ${ }^{1}$ Azman Hashim International Business School, Universiti Teknologi Malaysia, Kuala Lumpur, Malaysia \\ ${ }^{2}$ Faculty of Social Sciences, The University of the West Indies, St. Augustine, Trinidad and Tobago \\ Correspondence: Sumera Syed, AHIBS, Universiti Teknologi Malaysia, Jalan Sultan Yahya Petra, 54100, Kuala \\ Lumpur, Malaysia.
}

Received: January 13, 2022

Accepted: February 14, 2022

Online Published: February 22, 2022

doi:10.5539/ibr.v15n3p75

URL: https://doi.org/10.5539/ibr.v15n3p75

\begin{abstract}
The present study attempts to analyze the effect of consumers' autonomy and attitude on halal food purchase intention, especially in a collectivist culture. In addition, the effect of consumers' attitude on their autonomy while making up halal food purchase intention was also investigated. The responses from a sample of 308 respondents from the major cities of Pakistan were gathered with the help of an online questionnaire and then analyzed by using Partial Least Squares-Structural Equation Modeling (PLS-SEM). The results revealed a large and significant effect of consumers' attitude on their autonomy to make halal food purchase intention. Moreover, the effect of consumers' attitude on halal food purchase intention was found to be significant; whereas the effect of consumers' autonomy on halal food purchase intention was not found. Hence, the results indicate that consumers' autonomy, which is an innate psychological need of humans, is undermined by their attitude in collectivist cultures. The study was performed to analyze the impact of consumers' attitude on their autonomy; future studies may be performed to examine the impact of attitude on other basic psychological needs of competence, and relatedness. Furthermore, Pakistan was taken as the context of study, such future research endeavors may be carried out in other collectivist and even non-collectivist societies. The present study is believed to be the first ever to investigate the impact of attitude on autonomy, specifically in a collectivist society.
\end{abstract}

Keywords: attitude, autonomy, self-determination, collectivist culture, halal food purchase intention

\section{Introduction}

Islam is the fastest growing religion in the world, and it is predicted that with around 1.9 billion Muslims in Southeast Asia and the Middle East, Islam will surpass other religions by 2070 (Rudgard, 2017). Hence, marketing analysts believe that the halal food industry will be the most flourishing sector in the future. Notwithstanding, halal food purchase intention is among the most highly captured phenomenon by researchers in recent years because of the popularity of halal food among consumers irrespective of their religious faiths (Ali et al., 2017; Syed, Shah \& Ahmad, 2021). The main reason for halal food consumption by Muslims is Shariah compliance, whereas the acceptability and consumption of halal food by non-Muslims is primarily triggered by the basic eminent features of halal food such as its cleanliness, safety, and high quality, which is basically achieved through animal husbandry and slaughtering methods (Ansawi, Sukoco \& Fanani, 2018; Syed et al., 2021). Besides, earlier researchers have mostly used the "Theory of Reasoned Action (TRA)" or the "Theory of Planned Behavior" (TPB) and discovered several factors effecting halal food purchase intention, such as attitude, subjective norms, perceived behavioral control, religiosity, knowledge, etc. (Abu-Hussin et al., 2017; Elseidi, 2018; Soon \& Wallace, 2017; Suleman, Sibghatullah, \& Azam, 2021). However, both these theories assume that halal food purchase intention is influenced primarily by extrinsically motivated factors, whereas the role of self-determination in making up halal food purchase intention has been neglected by the researchers (Syed et al., 2021). Nevertheless, in recent years, a growing trend of studying intrinsically motivated, self-determined behaviors has been on the rise among marketing researchers because the behaviors performed under the influence of extrinsic motivation are more prone to external environmental factors and hence are not perennial, 
whereas intrinsically motivated behaviors are durable (Ryan \& Deci, 2019). Self-determination Theory (SDT), which was presented by Deci and Ryan (1985), is the most commonly used theory to understand intrinsic motivation and has been used in the last decade by several marketing researchers to investigate consumer behaviors (Gilal et al., 2019). Nonetheless, a few researchers emphasize the need to analyze both intrinsically and extrinsically motivated behaviors by examining constructs from both 'TRA' and 'SDT' (Widyarini \& Gunawan, 2018; Williams, Sun \& Masser, 2019).

SDT is based on the basic psychological needs of autonomy, competence, and relatedness, but it has been observed that very little knowledge exists among individuals about these basic psychological needs, though they are congenital and as important for well-being as are the physiological needs for survival (Ryan \& Deci, 2019; Syed et al., 2021). Moreover, the need for autonomy is the most debatable phenomenon among social science researchers and psychologists, especially in the context of culture. Autonomy is concerned with the self-control of individuals to carry out an activity that ultimately contributes to their growth, happiness, and satisfaction; and thus, it is often used interchangeably with "self-determination" (Ryan \& Deci, 2017). Nonetheless, Ryan and Deci (2000) emphasized that the need for autonomy is universal and not bound to any one culture. However, a number of researchers believe that autonomy is bound to individualistic western cultures, whereas individuals belonging to collectivist and specifically Asian cultures are indifferent to the need for autonomy (Iyengar \& Lepper, 1999; Park \& Chirkov, 2020). Other researchers contemplate whether humans are incapable of controlling their will and whether the concept of autonomy is a fallacy (Dorsey, 2015; Wegner, 2002). The ongoing, obscure debate about autonomy gives rise to the urge to dig deeply into the construct of autonomy. The present study, therefore, attempts to contribute to the already existing knowledge of autonomy by examining its significance in consumer behavior in a collectivist culture.

Nevertheless, autonomy has been described by Ryan and Deci (2017) as a highly intrinsic motivator to carry out internalized behaviors not only in the domain of psychology, but during recent years, marketing and social science researchers have also embraced autonomy to study consumer behaviors. Moreover, globalization, digitalization, and access to social media and new technological tools have resulted in more savvy consumers than ever before, who are also quite self-determined and autonomous in their decisions. Yet, it has been noted that the studies regarding the most captured domain of halal food are scarce in autonomy-related studies. Henceforth, the present research aims to understand the need for autonomy in the context of halal food purchase intention.

A comprehensive review of previous studies shows that attitude, a key component of TRA, is the strongest predictor of halal food purchase intention among all other determinants (Abu-Hussin et al., 2017; Ali et al., 2017; Bashir et al., 2018). Moreover, although attitudes are deemed intrinsic motivators; yet in collectivist societies, attitudes are shaped by social norms and, therefore, extrinsic elements play a role in the formation of attitudes (Leavell, 2017; Riemer et al., 2014). In other words, attitudes are not naturally intrinsic, unlike the need for autonomy, which is purely intrinsic; rather, though intrinsic in nature, attitude is based on extrinsic elements. Ryan and Deci (2017) argued that "the need for autonomy" or "self-determination" of an individual either flourishes or diminishes when subject to extrinsic factors. However, no significant research is available which evaluates the impact of an intrinsic motivator such as attitude, which has its roots in extrinsic factors, on a purely innate intrinsic motivator such as autonomy. The present research takes a step further to examine the influence of the attitude of consumers on their autonomy while making up their halal food purchase intention.

Furthermore, Pakistan was chosen as the context of study because Pakistan is purely a collectivist society, with around 98\% of the population being Muslims and believed to consume halal food (Mehfooz, 2021). However, no significant research on halal food, especially regarding autonomy, has been done with respect to Pakistani halal food consumers.

The aforementioned discussion could be encapsulated into the problem statement as: "To understand the influence of autonomy and attitude on halal food purchase intention while measuring the effect of consumers' attitude on their autonomy to make halal food purchase intention in a collectivist society."

\subsection{Literature Review}

\subsubsection{Collectivist Culture}

Culture is regarded as the umbrella covering the values, beliefs, and characteristics of individuals, describing their thoughts and actions as they are passed from generation to generation through communication (Heine, 2010). The concept of classification of cultures was very clearly illustrated by Geert Hofstede in 1983 in his book "Cultural Consequences," whereby he identified two broad categories of culture as "individualistic" and "collectivist" culture (Hofstede, 2011). Individualistic cultures are much more person-centric and are characterized by loosely 
knitted relationships in which members of society feel they are only responsible for themselves and their immediate families, whereas members of collectivist cultures are bonded in a network of tightly knitted family structures in which they expect and are expected by their family and peers to take care of each other without expecting any reward or incentive (Hofstede, 2011; Milner, Fodness, \& Speece, 1993; Xiao, 2021). Triandis (2001) has elaborated that individuals belonging to collectivist cultures prioritize societal and group goals over individual ones, and their social behaviors are far more dependent on external processes as compared to internal ones. Nevertheless, relatedness holds the utmost importance in Asian cultures, and individuals are interdependent on each other, which impacts their cognition and motivation (Markus \& Kitayama; 1991; Xiao, 2021). Moreover, Hofstede (1983) has identified that autonomy, pleasure, and wealth are a few very basic characteristics of a highly individualistic society, in contrast to a collectivist society, which is more focused on the satisfaction of the need for relatedness and the provision of items necessary for living rather than leading a luxurious life.

\subsubsection{Self-determination}

Deci and Ryan (1985) are known as the pioneers of the concept of self-determination, mainly because of the "self-determination theory (SDT)" that was proposed by them in their book "Self-Determination and Intrinsic Motivation in Human Behavior." They defined self-determination as an individual's propensity to act freely, confidently, and on their own. Deci and Ryan (1985) presented self-determination as a continuum ranging from non-self-determined behaviors to self-determined behaviors as explained in Figure 1. They demonstrated that non-self-determined behaviors gradually turn into extrinsically motivated behaviors and finally fall under intrinsic motivation with the passage of time, primarily when the need for autonomy is satisfied and the individual thinks that he is completely controlling his will (Ryan \& Deci, 2000). Henceforth, the transition from non-self-determined to self-determined behavior, primarily due to a satisfied need for autonomy, makes the researchers use the terms "autonomy" and "self-determination" reciprocally.

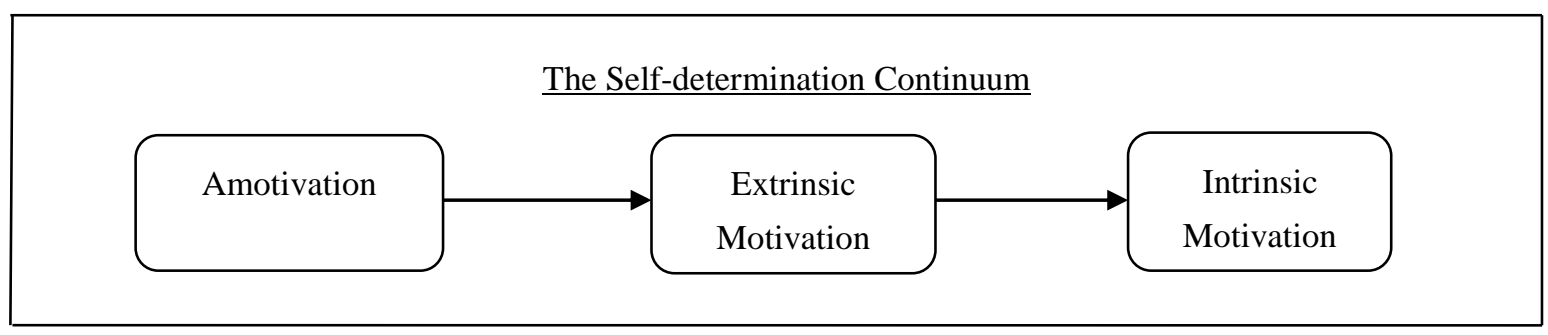

Figure 1. The Self-determination continuum adopted from Ryan, R. M. \& Deci, E. L. (2000)

The "need for autonomy" is one of the three basic psychological needs, along with "the need for competence" and "the need for relatedness", which laid the ground for SDT. SDT asserts that the three basic psychological needs trigger human beings to carry out an activity that ultimately leads to their growth and well-being (Ryan \& Deci, 2019). Hence, the satisfaction of innate psychological needs guarantees the rise of intrinsic motivation in an individual, which contributes to more stable and reliable behavior and is associated with the prosperity of the individual. Though the concept of intrinsic motivation in the domain of marketing has not yet been fully explored, a few researchers stress the use of SDT to determine intrinsically triggered purchase decisions (Gilal et al., 2019; Widyarini \& Gunawan, 2018).

\subsubsection{Autonomy}

The need for autonomy reflects the free will of individuals to perform tasks that are independent of any external environmental pressures (Ryan \& Deci, 2017; Syed et al., 2021), and is one of the three basic psychological needs (autonomy, competence, and relatedness) that serve as a pillar for the organismic meta-theory "SDT". However, "autonomy" has grabbed the attention of psychologists and social science researchers because of the ongoing controversy between critics and advocates of autonomy (Ryan \& Deci, 2006). While Ryan and Deci (2006) emphasized the need for the satisfaction of basic psychological needs for physical and mental well-being and growth, irrespective of any cultural differences, there are advocates of cross-cultural differences who criticize the universal nature of basic psychological needs, especially autonomy, and strongly contradict the argument of Ryan and Deci (2000) that autonomy is not culture-specific (Jordon, 1991). On the other hand, Ryan and Deci (2006) emphasized that cross-cultural researchers are using "autonomy" and "independence" interchangeably, when in fact there's a huge difference between the two. Nonetheless, Markus and Kityama (1991) argued that individuals in collectivist cultures share the same beliefs, goals, values, and interests and are therefore interdependent on each 
other since childhood (Cousins, 1989). Therefore, in collectivist cultures, where interdependence on the family is highly observed, the individual's autonomy is suppressed, unlike in individualistic cultures, where individuals are mostly independent (Oishi \& Diener, 2001).

In different consumer behavior studies, researchers have found an influence of autonomy on purchase intention (Chen, Li \& Liu, 2019; Gilal et al., 2019). However, the effect of autonomy on consumers' halal food purchase intentions is still scarcely found in studies.

\subsubsection{Attitude}

Attitude is an individual's evaluation of certain behaviors and has been shown to be a significant predictor of intentions (Ajzen, 1991). Though attitudes also describe the inner feelings of an individual, they are not as intrinsic as autonomy because of the extrinsic factors affecting them (Riemer et al., 2014; Leavell, 2017). Yet the reciprocal use of "personal preferences" and "attitudes" is quite popular among psychologists and social scientists (Riemer et al., 2014). Furthermore, in collectivist cultures, social norms are the basis of attitude formation, and though preferences shape such attitudes, these preferences are not necessarily personal but normative instead. In addition, in collectivist cultures, attitudes are shaped by the preferences of other members of society, including family, friends, and peers. Furthermore, just because individualistic cultures are symbolized by "autonomy," this does not imply that the need for autonomy has no influence on behaviors in collectivist cultures. Autonomy does affect behaviors in collectivist cultures, but the attitudes prevalent in collectivist cultures are more reflective of others' preferences (Riemer et al., 2014), which gives rise to the notion that in collectivist cultures, the need for autonomy is suppressed in the presence of less intrinsic factors such as attitudes, which are somewhat under the influence of extrinsic factors despite being intrinsic in nature.

The debate on attitude has been quite popular for ages; however, the "Theory of Reasoned Action (TRA)" presented by Ajzen and Fishbein (1980) is the most popular theory and is considered the pioneer in explaining the role of attitude in the formation of behavioral intentions and, thus, behaviors. TRA presents attitude and subjective norms as the two main determinants of behavior and intention. However, in non-western or collectivist cultures, subjective norms are infused into attitudes because attitudes are shaped by social norms in such cultures (Riemer et al., 2014).

As mentioned earlier, TRA and the extension of TRA, i.e., "Theory of Planned Behavior (TPB)", are the two major marketing theories that have been employed to predict purchase intention (Gilal et al., 2019). A thorough study of halal food literature shows that attitude significantly impacts halal food purchase intention (Ali et al., 2017; Bashir et al., 2018; Suleman et al., 2021).

The above mentioned discussion gave rise to the following hypotheses:

$\mathrm{H}_{1:}$ There is a significant impact of autonomy on halal food purchase intention.

$\mathrm{H}_{2}$ : There is a significant impact of attitude on halal food purchase intention.

$\mathrm{H}_{3:}$ There is a significant impact of attitude on autonomy.

\subsection{Conceptual Framework}

Based on the above debate, the conceptual framework has been presented in Figure 2. Autonomy and attitude are the independent variables predicting halal food purchase intention as hypothesized with $\mathrm{H}_{1}$ and $\mathrm{H}_{2}$; while the hypothesized relationship between attitude and autonomy is mentioned with $\mathrm{H}_{3}$. Thus, in other words, the conceptual framework demonstrates that there is the influence of autonomy on halal food purchase intention $\left(\mathrm{H}_{1}\right)$. In addition, $\mathrm{H}_{2}$ supposes that attitude influences halal food purchase intention. Furthermore, $\mathrm{H}_{3}$ indicates that attitude may have an influence on autonomy. 


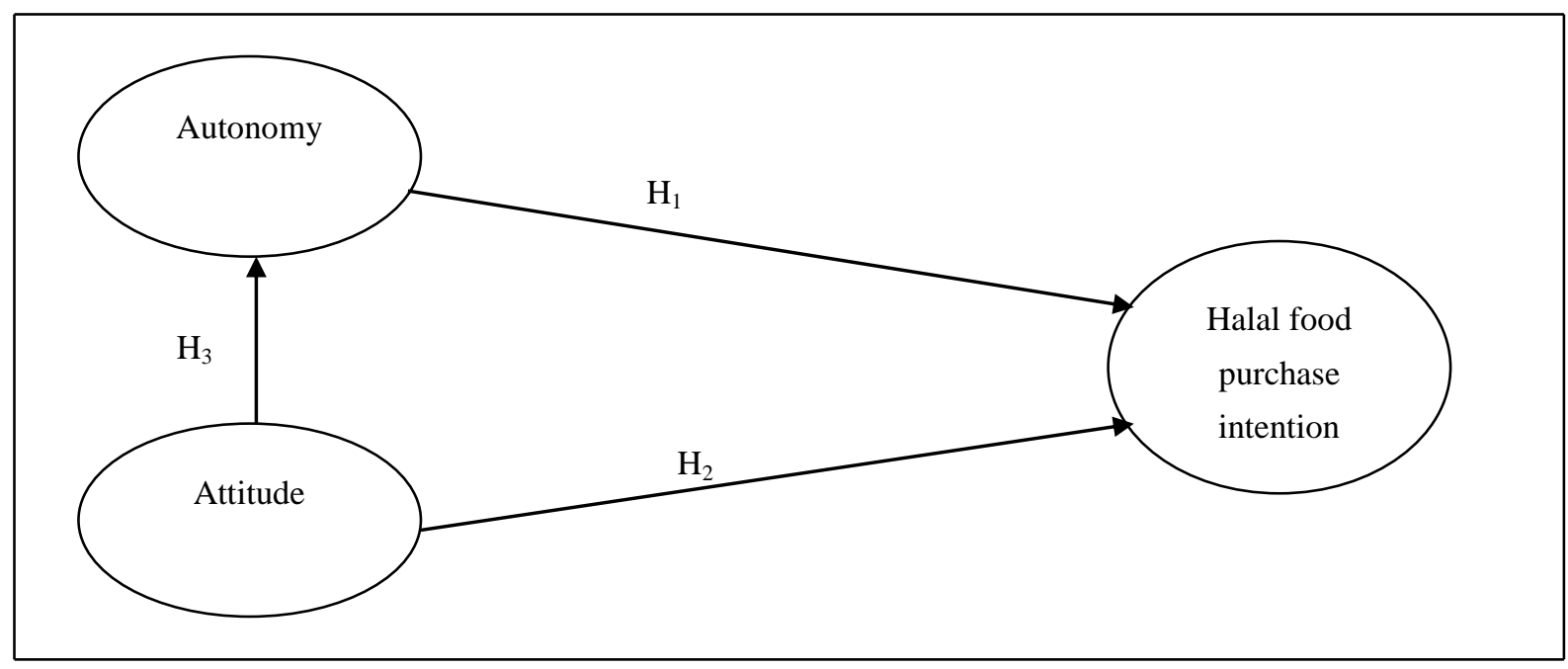

Figure 2. The Conceptual framework

\section{Methodology}

The study used quantitative technique and, thus, a deductive approach. The hypotheses were developed and an online questionnaire was used to collect the data. The data was then cleaned and analyzed for hypotheses testing by using Structural Equation Modeling.

\subsection{Questionnaire Development}

The items used for the questionnaire were adapted from previously available literature and then validated by academicians and industry professionals. A few items were deleted based on their opinion. A 5-point Likert scale (ranging from 1 for "strongly disagree" to 5 for "strongly agree") was used to analyze responses. The items for "autonomy" were taken from the studies conducted by den Broeck et al. (2010), Vlachopoulos and Michailidou (2006), and Ryan and Deci (2000); whereby the study performed by Khalek (2015) was used for the items of "attitude". The studies taken out by Widodo (2013), and Khalek (2015) were consulted to select the items for the 'halal food purchase intention. Then, a pilot study was conducted and exploratory factor analysis was performed, which finally revealed 4 items for "autonomy", 4 for "attitude", and 3 for "halal food purchase intention". The questionnaire was then updated to carry out the actual study.

\subsection{Data Collection}

The data was collected from the residents of Islamabad, Karachi and Lahore, which are the big cities of a collectivist society namely, Pakistan. Online questionnaires were distributed through social media platforms and 94.6\% response rate was obtained. After initial screening such as missing values, straight lining, outlier detection and common method bias, 308 usable responses were analyzed for final testing. Among the respondents were 184 females and 124 males. The majority $(71.4 \%)$ consisted of youth ranging between the ages 18 to 39 years; while $25.3 \%$ respondents were aged at 40 years and above. The respondents under 18 years contributed to $3.2 \%$ of the data. 187 respondents were living in individual family systems, whereas 121 were living in joint households.

\section{Results}

The Partial least square structural equation modeling (PLS-SEM) approach was used to analyze the data with the help of Smart PLS 3.3.3 software. The PLS-SEM approach was used because the data was not normal and PLS-SEM works well with non-parametric data (Hair et al., 2017). PLS-SEM is associated with the analysis of two types of models, i.e., "measurement model" and "structural model," whereby the measurement model primarily evaluates the reliability and validity of the model, and the structural model analyzes the hypotheses and relationships between exogenous and endogenous variables.

\subsection{Measurement Model Assessment}

The internal consistency reliability was established as all the values of Cronbach's alpha and composite reliability were found to be above 0.70 as recommended by Hair et al. (2017). Convergent validity was 
established because composite reliability values were above 0.70, AVE above 0.50 and factor loadings above 0.60 (Hair et al., 2017) as mentioned in Table 1 below. "Heterotrait-Monotrait" ratio (HTMT) values were found to be below 0.85 as shown in Table 2 as recommended by Henseler et al. (2015), thus establishing discriminant validity. VIF values were found to be 1.601 for both the constructs; hence, there was no multicollinearity.

Table 1. Reliability and Convergent Validity of Measurement Model

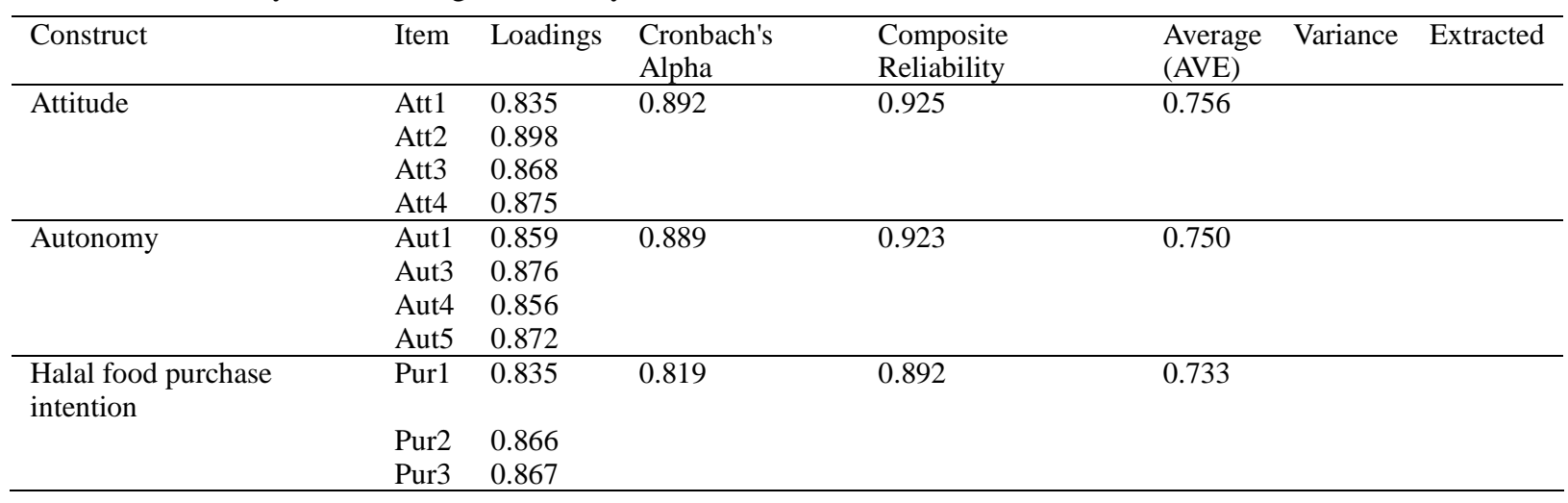

Table 2. Heterotrait-Monotrait (HTMT) Matrix

\begin{tabular}{llll}
\hline & Attitude & Autonomy & Halal food purchase intention \\
\hline Attitude & & & \\
Autonomy & 0.682 & & \\
Halal food purchase intention & 0.605 & 0.459 & \\
\hline
\end{tabular}

\subsection{Structural Model Assessment}

A bootstrapping technique performed at $95 \%$ confidence intervals was used to evaluate path coefficients (Table $3)$. The findings revealed that $\mathrm{H} 2(\beta=0.438$, $\mathrm{t}$-value $=6.304, \mathrm{p}<0.05)$ and $\mathrm{H} 3(\beta=0.613$, t-value $=13.149, \mathrm{p}<$ 0.05 ) were both supported, but $\mathrm{H} 1(\beta=0.134$, $\mathrm{t}$-value $=1.876, \mathrm{p}>0.05)$ was not. Therefore, the acceptance of $\mathrm{H} 2$ and $\mathrm{H} 3$ implies that attitude impacts both autonomy and halal food purchase intention; whereas the rejection of H1 leads to the conclusion that autonomy doesn't impact halal food purchase intention. Moreover, $\mathrm{f} 2$ was found to be 0.016 for the effect of autonomy on halal food purchase intention, 0.167 for the effect of attitude on halal food purchase intention, and 0.601 for the effect of attitude on autonomy. Cohen (1988) interpreted the f2 values of $0.02,0.15$, and 0.35 to be small, medium, and large effects, respectively; hence, the effect of autonomy on halal food purchase intention is negligible, the effect of attitude on halal food purchase intention is medium, and the effect of attitude on autonomy is very large.

Furthermore, the coefficient of determination $\mathrm{R}^{2}$ was found to be 0.375 for autonomy, indicating an explained variance of $37.5 \%$. On the other hand, $\mathrm{R}^{2}$ was 0.282 for halal food purchase intention which means $28.2 \%$ variance in halal food purchase intention is explained by the independent variables of autonomy and attitude. According to Cohens' (1988) criterion of 0.26 good, 0.13 moderate, and 0.02 weak values of $\mathrm{R}^{2}$, it was concluded that both the values of $\mathrm{R}^{2}$ fall into the good category.

Table 3. Hypothesis Testing and Model Assessment

\begin{tabular}{|c|c|c|c|c|c|c|c|}
\hline Hypothesis & Relationship & $\begin{array}{l}\text { Standardised } \\
\text { Beta }\end{array}$ & $\begin{array}{l}\text { Standard } \\
\text { Error }\end{array}$ & t-value & p-value & $\mathrm{f}^{2}$ & Decision \\
\hline $\mathrm{H}_{1}$ & $\begin{array}{l}\text { Autonomy }->\text { Halal } \\
\text { food purchase } \\
\text { intention }\end{array}$ & 0.134 & 0.072 & 1.876 & 0.061 & 0.016 & $\begin{array}{l}\text { Not } \\
\text { Supported }\end{array}$ \\
\hline $\mathrm{H}_{2}$ & $\begin{array}{l}\text { Attitude }->\text { Halal food } \\
\text { purchase intention }\end{array}$ & 0.438 & 0.069 & 6.304 & 0.000 & 0.167 & Supported \\
\hline $\mathrm{H}_{3}$ & Attitude $->$ Autonomy & 0.613 & 0.047 & 13.149 & 0.000 & 0.601 & Supported \\
\hline
\end{tabular}


In addition, the blindfolding procedure for the 'predictive relevance' of the model gave a Q2 value of 0.272 for autonomy and 0.2 for halal food purchase intention, which are both greater than 0 , thus witnessing the predictive relevance of the model. The SRMR value of $0.065<0.08$ shows model fit.

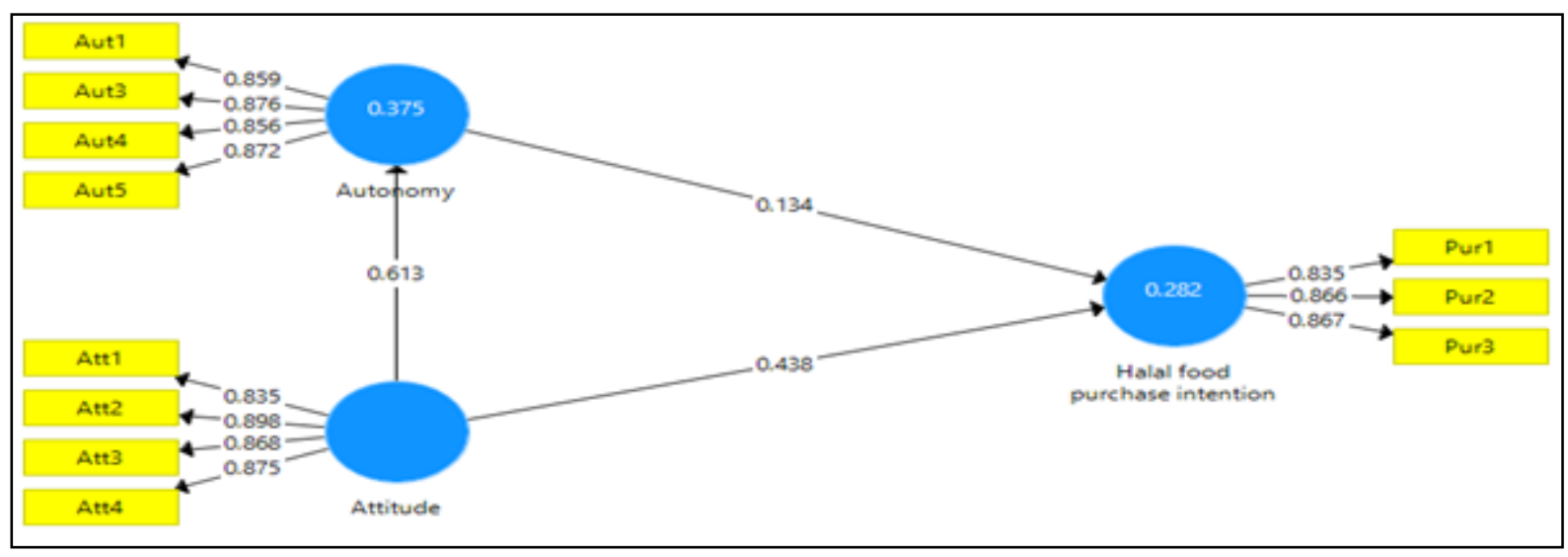

Figure 3. Structural Model

\section{Conclusion}

The findings illustrate that $\mathrm{H} 1$ was not supported, so the consumers' autonomy has no effect on their halal food purchase intention. This finding supports the notion that consumers belonging to the collectivist society of Pakistan are not autonomous in their decisions to purchase halal food, which conforms to the studies conducted by Oishi \& Diener (2001) that the need for autonomy is diminished in collectivist cultures.

As $\mathrm{H}_{2}$ was supported, so the attitude of consumers influences their halal food purchase intention, which is in line with the studies performed by Ali et al., (2017), Abu-Hussin et al. (2017), and Suleman et al., (2021), who examined the considerable impact of attitude on halal food purchase intention.

H3 was also supported; hence, it is concluded that the consumers' autonomy is undermined by attitude. Therefore, it supports the study by Ryan and Deci (2006) that the need for autonomy is thwarted in the presence of less intrinsic factors. Attitude is an intrinsic motivator, but it has foundations in extrinsic elements, which makes it less internalized as the natural inborn need for autonomy (Ryan \& Deci, 2017; Leavell, 2017).

The large effect size while determining the impact of attitude on autonomy clearly indicates that attitudes in collectivist cultures play a significant role in making up individuals' behavioral intentions, which ultimately influence their purchase decisions. Since the study has been conducted in a collectivist culture, this gets further supplemented with the norms and values that prevail in a collectivistic society; like Pakistan. Whereby, the decisions to purchase do not simply rest with an individual, rather these are significantly influenced by the social pressures i.e. family, peers, relatives, friends etc. However, this highlights the other important aspect of one's influencing factors, which are generally observed while the acts are being performed. Subsequently, the attitude is observed as a dominant role player in shaping individuals' decision making and purchase intentions, whereas the purely intrinsic factor that urges the individuals to make autonomous decisions for the purchase remains highly non-subversive in nature.

\subsection{Theoretical Implications}

The present study adds to the halal food literature by empirically investigating the relationship between attitude and autonomy for halal food purchase intention in a collectivist culture for the first time. The constructs "autonomy", "attitude", and "halal food purchase intention" were used to develop the framework, with attitude and autonomy as independent variables, whereas halal food purchase intention was used as a dependent variable. Moreover, the impact of attitude on autonomy was also analyzed, with attitude as an independent variable and autonomy as a dependent variable. The results revealed that attitude affects halal food purchase intention, while autonomy was not found to have any effect on halal food purchase intention.

\subsection{Practical Implications}

The study provides a platform for marketers to devise culturally specific strategies for the halal food industry. Moreover, collectivist customers are more influenced by attitudes shaped by social norms; hence, the same 
should be reflected in advertising and marketing campaigns devised for halal food. Importantly, because cultures shape consumer preferences, especially for those who travel to different countries for short-term or long-term stays. Such travel intentions of consumers tend to shape certain attitudes, which reciprocally affect the decision making of consumers, as per their own cultural norms and values. Hence, the study also supports the need to have a greater understanding of attitudes that are formed due to the consumers' own cultures, so the offerings can be tailored accordingly to the right fulfilment of the consumers' needs.

\section{Limitations and Recommendations}

The study was conducted only in one collectivist culture (Pakistan); it is recommended to test it further in different collectivist cultures like Malaysia and Indonesia, which are also big halal food hubs. Moreover, cross-cultural studies should also be performed to get a better understanding of halal food purchase intention.

Moreover, only the variable 'autonomy' from SDT was assessed for the present study, future research may be performed with the other two constructs, 'competence' and 'relatedness', to study their relationship with attitude as well as halal food purchase intention.

The study is cross-sectional in nature; longitudinal studies should be performed to analyze the behavior over the long term.

\section{References}

Abu-Hussin, M. F., Johari, F., Hehsan, A., Saiful, M., \& Nawawi, A. B. M. (2017). Halal purchase intention among the Singaporean Muslim minority. Journal of Food Products Marketing, 23(7), 769-782. https://doi.org/10.1080/10454446.2016.1141139

Ajzen, I. (1991). The theory of planned behaviour. Organizational Behavior and Human Decision Processes, 50(2), 179-221. https://doi.org/10.1016/0749-5978(91)90020-T

Ajzen, I., \& Fishbein, M. (1980). Understanding attitudes and predicting social behavior. Englewood Cliffs, NJ: Prentice-Hall.

Ali, A., Xiaoling, G., Sherwani, M., \& Ali, A. (2017). Factors affecting Halal meat purchase intention: Evidence from international Muslim students in China. British Food Journal, 119(3), 527-541. https://doi.org/10.1108/BFJ-10-2016-0455

Ansawi, N., Sukoco, B. M., \& Fanani, M. A. (2018). Halal products consumption in international chain restaurants among global Moslem consumers. International Journal of Emerging Markets, 13(5), 1273-1290. https://doi.org/10.1108/IJoEM-11-2017-0495

Bashir, A. M., Bayat, A., Olutuase, S. O., \& Latiff, Z. A. A. (2018). Factors affecting consumers' intention towards purchasing halal food in South Africa: A structural equation modeling. Journal of Food Products Marketing, 25(1), 26-48. https://doi.org/10.1080/10454446.2018.1452813

Chen, X., Fang, S., Li, Y., \& Wang, H. (2019). Does identification influence continuous e-commerce consumption? The mediating role of intrinsic motivations. Sustainability, 11(7), 1-20. https://doi.org/10.3390/su11071944

Cohen J. (1988). Statistical power analysis for the behavioral sciences (2nd ed.). Hillsdale, NJ: Laurence Erlbaum Associates.

Cousins, S. D. (1989). Culture and self-perception in Japan and the United Sates. Journal of Personality and Social Psychology, 56, 124-131. https://doi.org/10.1037/0022-3514.56.1.124

Deci, E. L., \& Ryan, R. M. (1985). The general causality orientations scale: Self-determination in personality. Journal of Research in Personality, 19(2), 109-134. https://doi.org/10.1016/0092-6566(85)90023-6

den Broeck, A. V., Vansteenkiste, M., De witte, H., Soenens, B., \& Lens, W. (2010). Capturing autonomy, competence, and relatedness at work: Construction and initial validation of the work-related basic need satisfaction scale. Journal of Occupational and Organizational Psychology, 83, 981-1002. https://doi.org/10.1348/096317909X481382

Dorsey, D. (2015). welfare, autonomy, and the autonomy fallacy. Pacific Philosophical Quarterly, 96(2), 141-164. https://doi.org/10.1111/papq.12069

El-Seidi, R. I. (2018). Determinants of halal purchasing intentions: evidences from UK. Journal of Islamic Marketing, 9(1), 167-190. https://doi.org/10.1108/JIMA-02-2016-0013

Gilal, F. G., Zhang, J., Paul, J., \& Gilal, N. G. (2019). The role of self-determination theory in marketing science: 
An integrative review and agenda for research. European Management Journal, 37(2019), 29-44. https://doi.org/10.1016/j.emj.2018.10.004

Hair, J. F. J., Hult, G. T. M., Ringle, C. M., \& Sarstedt, M. (2017). A primer on partial least squares structural equation modeling (PLS-SEM) (2nd ed.). Sage, Thousand Oaks, CA.

Heine, S. J. (2010). Cultural psychology in Handbook of Social Psychology. eds. S. T. Fiske, D. T. Gilbert, and G. Lindzey (Hoboken, NJ: John Wiley and Sons Inc.), 1423-1464.

Henseler, J., Ringle, C. M., \& Sarstedt, M. (2015). A new criterion for assessing discriminant validity in variance-based structural equation modeling. Journal of the Academy of Marketing Science, 43, 115-135. https://doi.org/10.1007/s11747-014-0403-8

Hofstede, G. (1983). Dimensions of national cultures in fifty countries and three regions. In Expiscations in Cross-cultural psychology, J.B. Deregowski, S. Dziurawiec, and R.C. Annis, eds., Lisse, Netherlands: Swets \& Zeitlinger, pp.335-355.

Hofstede, G. (2011). Dimensionalizing cultures: The Hofstede model in context. Online Readings Psychol. Cultu. 2. https://doi.org/10.9707/2307-0919.1014

Iyengar, S. S., \& Lepper, M. R. (1999). Rethinking the value of choice: A cultural perspective on intrinsic motivation. Journal of Personality and Social Psychology, 76, 349-366. https://doi.org/10.1037/0022-3514.76.3.349

Jordan, J. V. (1991). The relational self: A new perspective for understanding women's development. In: $J$. Strauss \& G. Goethals (Eds.), The self: Interdisciplinary approaches (pp. 136-149). Cambridge, MA: Harvard University Press. https://doi.org/10.1007/978-1-4684-8264-5_8

Khalek, A. B. A. (2015). Determinants influencing halal food consumption among generation Y Muslims in Malaysian private universities (Doctoral dissertation). Kuala Lumpur: University of Malaya.

Leavell, J. P. (2017). Controlling and informational planned behaviour: Self-determination theory and the theory of planned behaviour. Atlantic Marketing Journal, 5(3), 81-91. Retrieved from https://digitalcommons.kennesaw.edu/amj/vol5/iss3/6

Markus, H. R., \& Kitayama, S. (1991). Culture and the self: Implications for cognition, motion, and motivation. Psychological Review, 98, 224-253. https://doi.org/10.1037/0033-295X.98.2.224

Mehfooz, M. (2021). Religious freedom in Pakistan: A case study of religious minorities. Religions, 12(1), 51. MDPI AG. https://doi.org/10.3390/rel12010051

Milner, L. M., Fodness, D., \& Speece, M. W. (1993). Hofstede's research on cross-cultural work-related values: Implications for consumer behaviour. In: E-European Advances in Consumer Research Volume 1, eds. W. Fred Van Raaij and Gary J. Bamossy, Provo, UT : Association for Consumer Research, pp.70-76.

Oishi, S., \& Diener, E. (2001). Goals, culture, and subjective well-being. Personality \& Social Psychology Bulletin, 27, 1674-1682. https://doi.org/10.1177/01461672012712010

Park, M. S. A., \& Chirkov, I. V. (2020). Editorial: Culture, self, and autonomy. Frontiers in Psychology, 11, 736. https://doi.org/10.3389/fpsyg.2020.00736

Riemer, H., Shavitt, S., Koo, M., \& Markus, H. R. (2014). Preferences don't have to be personal: Expanding attitude theorizing with a cross-cultural perspective. Psychological Review, 121(4), 619-648. https://doi.org/10.1037/a0037666

Rudgard, O. (2017). Islam will be largest religion in the world by 2070, says report. Telegraph. Retrieved March 13, 2019 from www.telegraph.co.uk/news/2017/03/01/islam-will-largest-religion-world-2070-saysreport/

Ryan, R. M., \& Deci, E. L. (2000). Self-determination theory and the facilitation of intrinsic motivation, social development, and well-being. American Psychologist, 55(1), 68-78. https://doi.org/10.1037/0003-066X.55.1.68

Ryan, R. M., \& Deci, E. L. (2006). Self-regulation and the problem of human autonomy: Does psychology need choice, self-determination, and will? Journal of Personality, 74(6). https://doi.org/10.1111/j.1467-6494.2006.00420.x

Ryan, R. M., \& Deci, E. L. (2017). Self-determination theory: Basic psychological needs in motivation, development, and wellness. New York, NY, US: Guilford Press. https://doi.org/10.1521/978.14625/28806

Ryan, R. M., \& Deci, E. L. (2019). Chapter four - brick by brick: The origins, development, and future of 
self-determination theory. Advances in Motivation Science, 6(2019), 111-156.

https://doi.org/10.1016/bs.adms.2019.01.001

Soon, J. M., \& Wallace, C. (2017). Application of theory of planned behaviour in purchasing intention and consumption of Halal food. Journal of Nutrition \& Food Science, 47(5), 635-647. https://doi.org/10.1108/NFS-03-2017-0059

Suleman, S., Sibghatullah, A., \& Azam, M. (2021). Religiosity, halal food consumption, and physical well-being: An extension of the TPB. Cogent Business \& Management, 8(1), 1-18. https://doi.org/10.1080/23311975.2020.1860385

Syed, S., Shah. S. R. H., \& Ahmad, F. S. (2021). The influence of intrinsic motivational forces on consumers' product purchase intentions. Journal of Mediterranian Tourism Research, 1(2), 70-80. https://doi.org/10.5038/2770-7555.1.2.1006

Triandis, H. C. (2001). Individualism-collectivism and personality. Journal of Personality, 69, 907- 924. https://doi.org/10.1111/1467-6494.696169

Vlachopoulos, S. P., \& Michailidou, S. (2006). Development and initial validation of a measure of autonomy, competence, and relatedness in exercise: the basic psychological needs in exercise scale. Measurement in Physical Education and Exercise Science, 10(3), 179-201. https://doi.org/10.1207/s15327841mpee1003_4

Wegner, D. M. (2002). The illusion of conscious will. MIT Press. https://doi.org/10.7551/mitpress/3650.001.0001

Widodo, T. (2013). The influence of Muslim consumer's perception toward halal food product on attitude and purchase intention at retail stores. 3 Inovbiz, l(1), 3-20.

Widyarini, L. A., \& Gunawan, S. (2018). Predicting consumer purchase intention on fashion products in online retailer: Integration of self-determination theory and theory of planned behavior. International Journal of Emerging Research in Management \& Technology, 6(9), 7-18. https://doi.org/10.23956/ijermt.v6i9.78

Williams, L. A., Sun, J., \& Masser, B. (2019). Integrating self-determination theory and the theory of planned behaviour to predict intention to donate blood. Transfusion Medicine, 29(1), 59-64. https://doi.org/10.1111/tme.12566

Xiao, W. S. (2021). The role of collectivism-individualism in attitudes toward compliance and psychological responses during the COVID-19 pandemic. Frontiers in Psychology, 12, 5063.

https://doi.org/10.3389/fpsyg.2021.600826

\section{Copyrights}

Copyright for this article is retained by the author(s), with first publication rights granted to the journal.

This is an open-access article distributed under the terms and conditions of the Creative Commons Attribution license (http://creativecommons.org/licenses/by/4.0/). 